\title{
The anti-IgE antibody omalizumab reduces exacerbations and steroid requirement in allergic asthmatics
}

\author{
M. Solèr*, J. Matz" ${ }^{\#}$ R. Townley ${ }^{\Uparrow}$, R. Buhl ${ }^{+}$, J. O’Brien ${ }^{\S}$, H. Fox ${ }^{f}$, J. Thirlwellf , N. Gupta**, \\ G. Della Cioppa ${ }^{f}$
}

The anti-IgE antibody omalizumab reduces exacerbations and steroid requirement in allergic asthmatics. M. Solèr, J. Matz, R. Townley, R. Buhl, J.O'Brien, H. Fox, J. Thirlwell, N. Gupta, G. Della Cioppa. (C)ERS Journals Ltd 2001.

ABSTRACT: The clinical benefit and steroid-sparing effect of treatment with the antiimmunoglobulin-E (IgE) antibody, omalizumab, was assessed in patients with moderateto-severe allergic asthma.

After a run-in period, 546 allergic asthmatics (aged 12-76 yrs), symptomatic despite inhaled corticosteroids (500-1,200 $\mu \mathrm{g}$ daily of beclomethasone dipropionate), were randomized to receive double-blind either placebo or omalizumab every 2 or 4 weeks (depending on body weight and serum total IgE) subcutaneously for 7 months. A constant beclomethasone dose was maintained during a 16-week stable-steroid phase and progressively reduced to the lowest dose required for asthma control over the following 8 weeks. The latter dose was maintained for the next 4 weeks. Asthma exacerbations represented the primary variable.

Compared to the placebo group, the omalizumab group showed $58 \%$ fewer exacerbations per patient during the stable-steroid phase $(\mathbf{p}<0.001)$. During the steroid-reduction phase, there were $52 \%$ fewer exacerbations in the omalizumab group versus the placebo group $(\mathrm{p}<\mathbf{0 . 0 0 1})$ despite the greater reduction of the beclomethasone dosage on omalizumab $(p<0.001)$. Treatment with omalizumab was well tolerated. The incidence of adverse events was similar in both groups.

These results indicate that omalizumab therapy safely improves asthma control in allergic asthmatics who remain symptomatic despite regular use of inhaled corticosteroids and simultaneous reduction in corticosteroid requirement.

Eur Respir J 2001; 18: 254-261.
*Pulmonary Division, University Hospital, Basel, Switzerland, "\#Atlantic Asthma \& Allergy Center Inc., Baltimore, USA, Creighton University School of Medicine, Omaha, USA, ${ }^{+}$Johannes-Gutenberg-Universitat III, Medizinische Klinik und Poliklinik, Mainz, Germany, ${ }^{\S}$ City Park Medical Centre, Capetown, South Africa, ${ }^{f}$ Novartis Horsham Research Centre, Horsham, England, **Novartis Pharmaceuticals Corporation, East Hanover, USA.

Correspondence: M. Solèr, Pulmonary Division, University Hospital, Petersgraben 4, CH-4031 Basel, Switzerland. Fax: 41612654587

Keywords: Airway inflammation allergic asthma

anti-allergic drugs

anti-immunoglobulin-E antibody immunoglobulin-E

omalizumab

Received: October 262000

Accepted after revision April 52001

This study was supported by Novartis Pharma AG, Basel, Switzerland, and Genentech Inc., South San Francisco, CA, USA.
Patients with mild and moderate asthma are usually well controlled by inhaled corticosteroids and $\beta_{2}$ adrenoceptor agonists [1-5] but some patients are more difficult to manage and remain symptomatic despite high dose inhaled corticosteroids and suffer from frequent exacerbations [4, 5]. This indicates persistent airway inflammation due to insufficient response or poor compliance to the prescribed corticosteroid regimen.

A central pathophysiological mechanism of allergic inflammation is the release of a number of proinflammatory mediators, including histamine, prostaglandins, leukotrienes, chemokines and cytokines, when the allergen binds to the immunoglobulin-E (IgE) located on the surface of effector cells [6-10]. Patients with allergic asthma of all ages have higher than normal serum IgE levels and these correlate with the heightened bronchoconstrictor response to a variety of stimuli and the occurrence of symptoms [11-14]. An
IgE-mediated inflammatory response may therefore, contribute to the persistence of airway hyperresponsiveness and symptoms in allergic asthmatics.

In this context, the recent development of an antiIgE antibody has opened a promising approach to the management of allergic asthma and other allergic inflammatory disorders [15-20]. The use of this agent dramatically reduces the serum concentrations of free IgE immediately after the first injection [17] and IgE blockade results in the attenuation of both early and late asthmatic responses to allergen inhalation, reduced eosinophil count in the sputum, decreased airway hyperresponsiveness, and improved symptom control in patients with allergic asthma [15-17]. The validity of this approach is supported by the results of studies in patients with seasonal allergic rhinitis, where the clinical efficacy of the anti-IgE antibody was related to the reduction in serum free $\mathrm{IgE}$ concentrations [19, 20]. 
Omalizumab (Xolair ${ }^{\mathrm{TM}}$ ), also referred to as rhuMAb-E25 in the literature [15-20], is a recombinant humanized monoclonal antibody [21] that recognizes $\operatorname{IgE}$ at the same site as the high-affinity receptor for IgE (FceRI) [22]. It forms complexes with circulating free IgE and prevents the binding of $\operatorname{IgE}$ to the high- and low-affinity receptors on cell membranes. It, therefore, impedes the recognition of the allergen by the effector cells such as mast cells, eosinophils, macrophages and dendritic cells, and inhibits their allergen-induced activation [23-25]. The antibody does not bind to cell-bound $\operatorname{IgE}$ and, therefore, does not trigger cell activation by crosslinking of the $\operatorname{IgE}$ molecules on cell membranes.

When administered by intravenous injection in patients with moderate-to-severe allergic asthma [17], this agent was well tolerated. It improved asthma control and quality of life compared to placebo, and allowed a significant reduction in the dose of both inhaled and oral corticosteroids [17].

The aim of this study was to evaluate the efficacy, safety and corticosteroid-sparing effect of omalizumab administered subcutaneously in allergic asthma.

\section{Materials and methods}

\section{Patients}

Eligible subjects were patients aged $12-75$ yrs with a diagnosis of asthma of at $\geqslant 1 \mathrm{yr}$ duration who met the standard criteria of the American Thoracic Society (ATS) [26] and the following additional criteria: a positive skin-prick test to at least one of the allergens Dermatophagoides farinae, D. pteronyssinus, dog or cat; serum total IgE level $\geqslant 30$ and $\leqslant 700$ International Units (IU) $\cdot \mathrm{mL}^{-1}$ and body weight $\leqslant 150 \mathrm{~kg}$ to allow optimal dosing of omalizumab; baseline forced expiratory volume in one second (FEV1) off bronchodilators $\geqslant 40 \%$ and $\leqslant 80 \%$ of predicted increasing by $\geqslant 12 \%$ within 30 min of taking inhaled salbutamol; a mean total daily symptom score of $\geqslant 3.0$ (maximum 9) during the 14 days prior to randomization; treatment with inhaled corticosteroids in doses equivalent to $500-1,200 \mu \mathrm{g}$ of beclomethasone dipropionate (BDP) per day for $\geqslant 3$ months prior to randomization and use of $\beta_{2}$-adrenoceptor agonists on an as-needed or regular basis. Asthma had to be stable, with no significant change in regular medication and no acute exacerbation requiring additional corticosteroid treatment for $\geqslant 1$ month prior to the screening visit. Patients regularly taking oral corticosteroids were not included.

The study protocol was approved by the institutional review board at each site, and all patients or their parents or guardians, when appropriate, gave written informed consent.

\section{Study design}

This was a multicentre, randomized, double-blind, placebo-controlled, parallel-group study. After a runin period of 4-6 weeks, patients were randomized to receive either placebo or omalizumab subcutaneously for 7 months. A table incorporating body weight and total IgE at screening was used to ensure omalizumab administration of $\geqslant 0.016 \mathrm{mg} \cdot \mathrm{kg}$ body weight ${ }^{-1}$ per International Units of total serum IgE $\cdot \mathrm{mL}^{-1}$ every 4 weeks (table 1). For patients requiring 150-300 mg omalizumab, administration was at 4-week intervals. For patients requiring $450-750 \mathrm{mg}$ omalizumab, the monthly dose was divided into two equal portions administered at 2-week intervals to minimize the number of injections at one time and still maintain adequate drug levels.

The use of rescue medication with salbutamol, delivered by a pressurized metered-dose inhaler (100 $\mu \mathrm{g}$ per puff), was allowed throughout the study.

During run-in, all patients were switched to inhaled BDP using the dose at which they were stable. This dose was maintained constant during the first 16 weeks of the study (stable-steroid phase). In the following 12 weeks (steroid-reduction phase) all patients were seen every 2 weeks. The BDP dose was reduced by $25 \%$ of the baseline dose at each visit for 8 weeks until total elimination, or until there was a decrease in FEV1 of $\geqslant 20 \%$ compared to the last measurement of the previous phase (last week of runin for the stable-steroid phase) or the development of an event defining asthma worsening as described below. If there was a decrease in FEV 1 of $\geqslant 20 \%$, or asthma worsening occurred, the previous dose of BDP was resumed. The lowest BDP dose required for asthma control was held for the remaining 4 weeks.

Serum free IgE levels were measured at different time points before and during treatment by a published method [18].

\section{Outcome measures}

The primary efficacy variables were the number of asthma exacerbations experienced per patient during the stable-steroid phase and the steroid-reduction phase of the study.

Patients were provided with written instructions to contact the investigator if any of the following events, indicating asthma worsening, occurred: deterioration of symptoms requiring an urgent or unscheduled visit;

Table 1. - Omalizumab dosage $(\mathrm{mg})$ and dosing schedule based on baseline total serum immunoglobulin (Ig)-E and body weight

\begin{tabular}{lccccc}
\hline \multirow{2}{*}{$\begin{array}{l}\text { Baseline IgE } \\
\text { IU·mL }\end{array}$} & \multicolumn{5}{c}{ Body weight kg } \\
\cline { 2 - 6 } & $30-60$ & $>60-70$ & $>70-80$ & $>80-90$ & $>90-150$ \\
\hline $30-100$ & 150 & 150 & 150 & 150 & 300 \\
$>100-200$ & 300 & 300 & 300 & 300 & 225 \\
$>200-300$ & 300 & 225 & 225 & 225 & 300 \\
$>300-400$ & 225 & 225 & 300 & 300 & \\
$>400-500$ & 300 & 300 & 375 & 375 & \\
$>500-600$ & 300 & 375 & & & \\
$>600-700$ & 375 & & & & \\
\hline
\end{tabular}

The doses in bold are every 2 weeks whilst the others are every 4 weeks. IU: International Units. 
peak expiratory flow (PEF) $<50 \%$ of patient's personal best; decrease in morning PEF $\geqslant 20 \%$ on $\geqslant 2$ of 3 successive days, compared to the last week of the previous phase (last week of run-in for the stablesteroid phase); $a \geqslant 50 \%$ increase in rescue medication on $\geqslant 2$ of 3 successive days, compared to the average use for the last week of the previous phase and exceeding eight puffs of salbutamol per day; $\geqslant 2$ of 3 successive nights with awakening due to asthma symptoms requiring rescue medication. In the evaluation of patients with worsening of asthma and in the management of acute exacerbations, the investigators were to adhere to current guidelines [1].

For efficacy analysis, asthma exacerbation was defined as a worsening of symptoms requiring treatment with systemic corticosteroids or doubling the baseline dose of BDP determined during the run-in period.

Secondary variables were the number of patients experiencing at least one asthma exacerbation during both the stable-steroid and the steroid-reduction phases, per cent reduction in the BDP dose at the end of the steroid-reduction phase as a continuous variable and by category, salbutamol rescue use, asthma symptom scores, morning PEF and FEV1 as $\%$ predicted.

Symptoms of asthma, morning PEF and the number of inhalations of rescue medication during the day and at night were recorded daily in the patient diary. Patients used a 4-point scale to rate their symptoms during the day and at night, with 0 indicating no symptoms and 4 indicating breathing problems at rest with major discomfort that limited routine activity during the day and provoked nighttime symptoms despite the use of rescue medication. The total score was also computed as the sum of the daytime and nocturnal scores plus morning score of yes $=1$ or no $=0$ for symptoms on awakening, with a maximum score of 9.

Quality of life was assessed as an additional efficacy variable but, due to space limitations, the results will be published separately.

\section{Statistical analysis}

Statistical analyses were performed using all randomized patients (intent-to-treat population). The number of asthma exacerbations per patient and the number of patients experiencing at least one asthma exacerbation were analysed in each phase using the generalized Cochran-Mantel-Haenszel test (van Elteren test) stratified by dosing schedule (2 or 4 weekly dosing). An a priori adjustment was made for patients who discontinued prematurely within either phase adding 1 exacerbation for every 2 weeks (of missed treatment phase) to any observed asthma exacerbation count for that phase. For patients discontinuing in the stable-steroid phase to be included in the steroid-reduction phase, the asthma exacerbation counts were taken as the maximum observed within the steroid-reduction phase+1. In order to avoid duplication, asthma exacerbations were not counted as adverse events unless they caused hospitalization (serious adverse event by default).

The per cent reduction in the BDP dose and the proportion of patients who reduced the BDP use were analysed using the generalized Cochran-MantelHaenszel test stratified by dosing schedule. Subjects who did not enter the steroid-reduction phase were included in the analysis with $0 \%$ BDP reduction.

All the other efficacy variables were analysed by the generalized Cochran-Mantel-Haenszel test, the Cochran-Mantel-Haenszel test or by the analysis of covariance with baseline values as a covariate, as appropriate. During the steroid-reduction phase, the analysis of these variables was performed post hoc.

The study was powered to show a difference in the number of asthma exacerbations in both phases, using the binomial approximation to the normal distribution. Based on the results of a previous study [17], it was anticipated that $68 \%$ and $69 \%$ of the patients on placebo and $80 \%$ and $82 \%$ of the patients on omalizumab would not experience an asthma exacerbation in the stable-steroid and steroid-reduction phases, respectively. To achieve this, 550 patients were to be randomized. These calculations were based on $\geqslant 85 \%$ power and $5 \%$ significance level.

\section{Results}

\section{Patients}

A total of 546 patients were randomized: 274 to omalizumab and 272 to placebo. Four-hundred and eighty-seven patients completed the study: 255 on omalizumab and 232 on placebo.

Twice as many patients in the placebo group (40, $14.7 \%)$ as in the omalizumab group $(19,6.9 \%)$ discontinued prematurely. Of the 19 patients who discontinued omalizumab, $13(4.7 \%)$ discontinued during the stable-steroid phase and $6(2.2 \%)$ during the steroid-reduction phase, compared to $27(9.9 \%)$ and $13(4.8 \%)$ discontinuing placebo. Fourteen patients $(5.1 \%)$ on placebo versus three patients $(1.1 \%)$ on omalizumab withdrew their consent. Eleven patients (three on omalizumab and eight on placebo) discontinued because of unsatisfactory therapeutic effect. No patient in the omalizumab group withdrew due to an adverse event versus five patients $(1.8 \%)$ in the placebo group.

A summary of the demographic and baseline characteristics is reported in table 2. The treatment groups were well balanced with respect to demographics.

\section{Change in serum free immunoglobulin-E}

In the patients on omalizumab, across the dosing regimens, median serum free $\mathrm{IgE}$ ranged from $145-1,246 \mathrm{ng} \cdot \mathrm{mL}^{-1}\left(60-515 \mathrm{IU} \cdot \mathrm{mL}^{-1}\right)$ at baseline, $11-$ $17 \mathrm{ng} \cdot \mathrm{mL}^{-1}\left(5-7 \mathrm{IU} \cdot \mathrm{mL}^{-1}\right)$ predose at the end of the stable-steroid phase, and $12-19 \mathrm{ng} \cdot \mathrm{mL}^{-1}\left(5-8 \mathrm{IU} \cdot \mathrm{mL}^{-1}\right)$ predose at week 24 of the treatment period. The reduction in serum free IgE from baseline during the treatment period ranged $89-99 \%$. 
Table 2.-Summary of demographic, background and baseline characteristics of the intent-to-treat population

\begin{tabular}{lcc} 
& Omalizumab & Placebo \\
\hline Subjects n & 274 & 272 \\
Sex M/F & $141 / 133$ & $127 / 145$ \\
Race Caucasian/other & $256 / 18$ & $242 / 30$ \\
Age yrs & $40.0(12-76)$ & $39.0(12-72)$ \\
Duration of asthma yrs & $20.3(2-68)$ & $19.1(1-63)$ \\
Smoking status & & \\
$\quad$ Nonsmoker & $213(77.7)$ & $207(76.1)$ \\
$\quad$ Exsmoker & $61(22.3)$ & $65(23.9)$ \\
$\begin{array}{l}\text { Daily BDP dose } \mu g \\
\text { Serum total IgE }\end{array}$ & $769.0(500-1600)$ & $772.1(200-2000)$ \\
$\quad$ IU·mL & $223.1(21-785)$ & $205.6(22-814)$ \\
FEV1 L & $2.53(1.00-5.05)$ & $2.52(0.64-5.05)$ \\
FEV1 \% pred & $69.8(30-112)$ & $69.9(22-109)$ \\
FEV1 reversibility \% & $26.4(10-86)$ & $25.8(11-103)$ \\
Asthma severity & & \\
$\quad$ Moderate & $214(78.1)$ & $213(78.3)$ \\
$\quad$ Severe & & $59(21.7)$ \\
History of & $60(21.9)$ & $28(10.3)$ \\
$\quad$ Atopic dermatitis & $24(8.8)$ & $177(65.1)$ \\
$\quad$ Seasonal allergic & $183(66.8)$ & \\
$\quad$ rhinitis & & \\
$\quad$ Perennial allergic & $213(77.7)$ & $209(76.8)$ \\
$\quad$ rhinitis & & \\
\hline
\end{tabular}

Data presented as mean (range) or $\mathrm{n}(\%)$ unless otherwise stated. M: male; F: female; BDP: beclomethasone dipropionate; IgE: immunoglobulin-E; FEV1: forced expiratory volume in one second; IU: International Units. ${ }^{\#}$ : per cent increase in FEV1 from baseline within $30 \mathrm{~min}$ of taking $200 \mu \mathrm{g}$ inhaled salbutamol; ${ }^{+}$: baseline FEV $1 \leqslant 65 \%$ pred and a mean total symptom score of $>4$ for the last 14 days of the run-in period.

\section{Asthma exacerbations}

The analysis of the number of asthma exacerbations per patient in the intent-to-treat population demonstrated statistically significant differences between omalizumab and placebo in favour of omalizumab for both stable-steroid and steroid-reduction phases $(\mathrm{p}<0.001)$ (table 3$)$. The same analysis carried out after removal of patients with major protocol violations gave similar results (data not shown).

The percentage of patients experiencing at least one exacerbation was also significantly lower in the omalizumab group than in the placebo group for both phases $(\mathrm{p}<0.001)$ (table 3$)$.

Approximately $80 \%$ of asthma exacerbations in both treatment groups were treated with systemic corticosteroids.

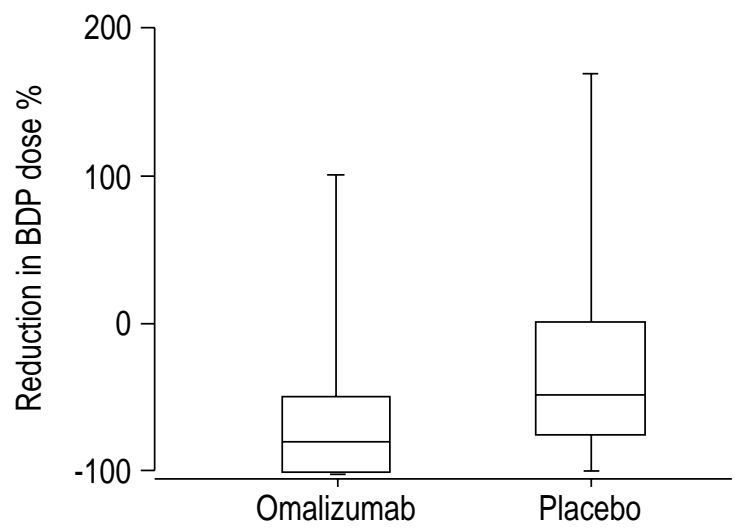

Fig. 1.-Box-and-whisker plot showing medians with interquartile range and minimum and maximal values for the per cent reduction in the prescribed dose of inhaled beclomethasone dipropionate (BDP) at the end of the steroid-reduction phase (week 28) compared to the stable-steroid phase. Intent-to-treat population. $\mathrm{p}<0.001$.

Reduction in the beclomethasone dipropionate dose and beclomethasone dipropionate withdrawal

At the end of the treatment period, the per cent reduction in the daily BDP dose from the starting dose was significantly greater in the omalizumab group than in the placebo group (fig. 1). The prescribed daily dose at the end of the steroid-reduction phase (for those patients who reached 28 weeks of treatment) was significantly lower on omalizumab (median: $100 \mu \mathrm{g}$, interquartile range: $0-400 \mu \mathrm{g}$ ) than on placebo (median: $300 \mu \mathrm{g}$, interquartile range: $100-600 \mu \mathrm{g}$ ) $(\mathrm{p}<0.001)$.

The proportion of patients who were able to reduce the BDP dose at the end of the steroid-reduction period compared to the stable-steroid phase was significantly higher in the omalizumab group than in the placebo group $(\mathrm{p}<0.001)$. The proportion of patients who were able to reduce the BDP dose by $\geqslant 50 \%$ was $79 \%$ on omalizumab and $55 \%$ on placebo. Furthermore, $43 \%$ of the patients on omalizumab withdrew BDP completely compared to $19 \%$ on placebo.

\section{Symptom score and rescue medication use}

The median total asthma symptom scores over the two phases of the study are reported by treatment in figure 2. Statistically significant differences in favour

Table 3. - Asthma exacerbations during the stable-steroid and steroid-reduction phases in the intent-to-treat population

\begin{tabular}{lcccccc}
\hline & \multicolumn{2}{c}{ Stable-steroid phase } & & \multicolumn{2}{c}{ Steroid-reduction phase } \\
\cline { 2 - 3 } & Omalizumab & Placebo & & Omalizumab & Placebo \\
\hline $\begin{array}{lllll}\text { Asthma exacerbations per petient } \\
\text { Patients with } \geqslant 1 \text { asthma exacerbations }\end{array}$ & $\begin{array}{c}0.28(0.15-0.41) \\
35(12.8)\end{array}$ & $\begin{array}{c}0.66(0.49-0.83) \\
83(30.5)\end{array}$ & & $\begin{array}{c}0.36(0.24-0.48) \\
43(15.7)\end{array}$ & $\begin{array}{c}0.75(0.58-0.92) \\
81(29.8)\end{array}$ \\
\hline
\end{tabular}

Data were analysed by the generalized Cochran-Mantel-Haenszel test (van Elteren test), and presented as mean $(95 \%$ confidence interval) or $\mathrm{n}(\%) . \mathrm{p}<0.001$. 


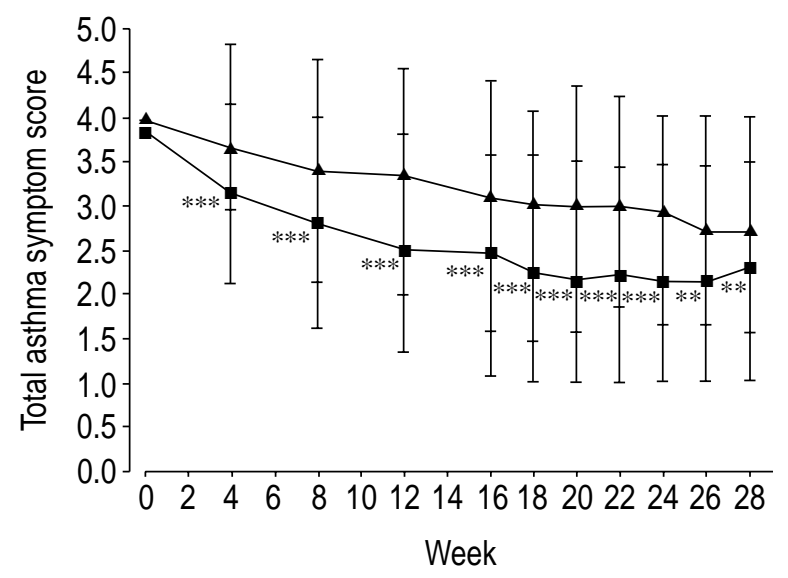

Fig. 2.-Total symptom scores during the stable-steroid (weeks $0-15$ ) and steroid-reduction phases (weeks 15-28). Intent-to-treat population. Data are median sums of the daytime scores, nocturnal scores and morning scores with interquartile range. $\boldsymbol{\Delta}$ : placebo; 口: omalizumab. $* *: \mathrm{p} \leqslant 0.01$ versus placebo; ***: $\mathrm{p} \leqslant 0.001$ versus placebo.

of omalizumab were seen during the entire stablesteroid phase. The improvement of symptoms in the omalizumab group persisted during the steroidreduction phase despite the greater reduction in the BDP dose on omalizumab. The beneficial effect of omalizumab was particularly evident for symptoms occurring during the night (fig. 3).

The median number of puffs of rescue medication was also lower in the omalizumab group than in the placebo group during the entire period of treatment (fig. 4). The difference in favour of omalizumab was statistically significant during the stable-steroid phase and remained significant during the steroid-reduction phase despite the more marked reduction in the BDP dosage on omalizumab.

\section{Morning peak expiratory flow and forced expiratory} volume in one second

The analysis of mean morning PEF revealed statistically significant differences between treatments in favour of omalizumab at all time points of the stable-steroid phase. This improvement continued during the steroid-reduction phase (fig. 5).

FEV1 was significantly better in the omalizumab group than in the placebo group between weeks 4 and 12 of the stable-steroid phase (fig. 5b). During the steroid-reduction phase, mean FEV1 values were significantly higher on omalizumab than on placebo between weeks 18 and 28 (fig. 5b).

\section{Safety and tolerability}

There were no deaths in this study. Nine (3.3\%) patients on omalizumab and three $(1.1 \%)$ patients on placebo had serious adverse events, excluding asthma exacerbations. Those on omalizumab were traumatic finger amputation, depression, appendicitis, flu-like syndrome, suspected eosinophilic granuloma of the
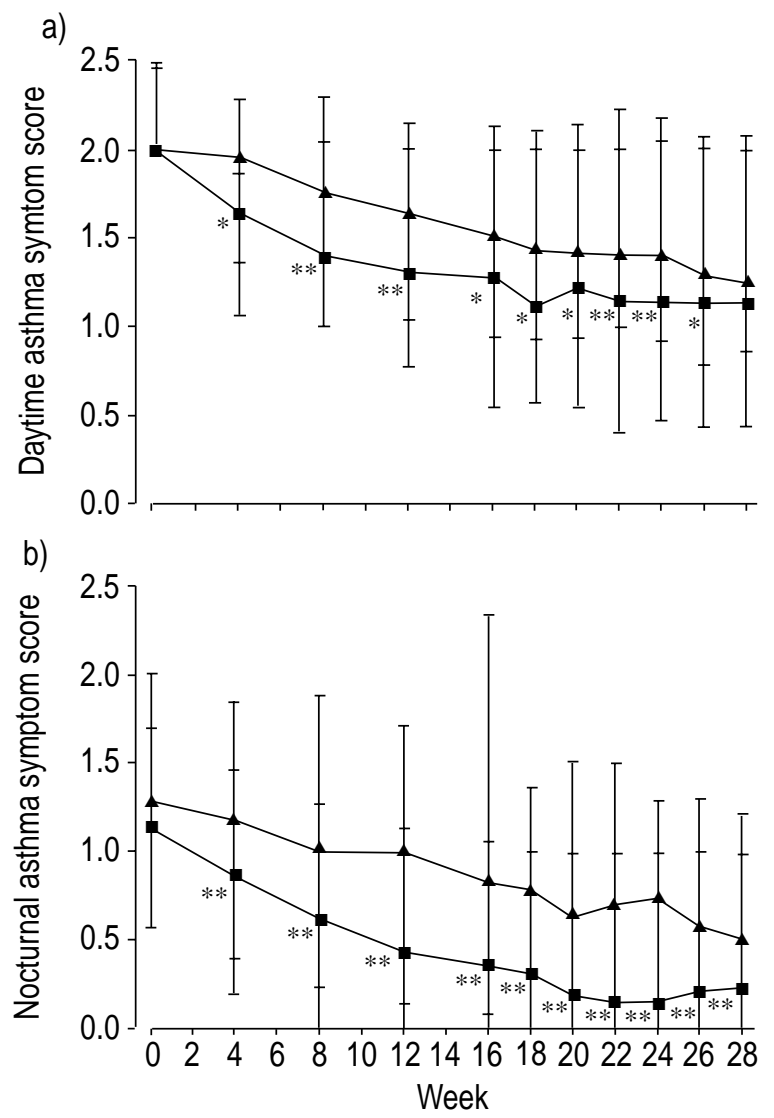

Fig. 3.-a) Daytime symptom scores during the stable-steroid (weeks 0-15) and steroid-reduction phases; b) nocturnal symptom scores during the sable-steroid and steroid-reduction phases (weeks 15-28). Intent-to-treat population. Data are medians with interquartile range. $\boldsymbol{\Delta}$ : placebo; $\mathbf{\square}$ : omalizumab. $*$ : $\mathrm{p}<0.05 ; * *: \mathrm{p}<0.01$ versus placebo.

skull, intestinal villous adenoma with dysplasia, infectious mononucleosis, squamous cell carcinoma of the face, and left arm fractures. Those in the placebo group were angina pectoris, tachyarrhythmia,

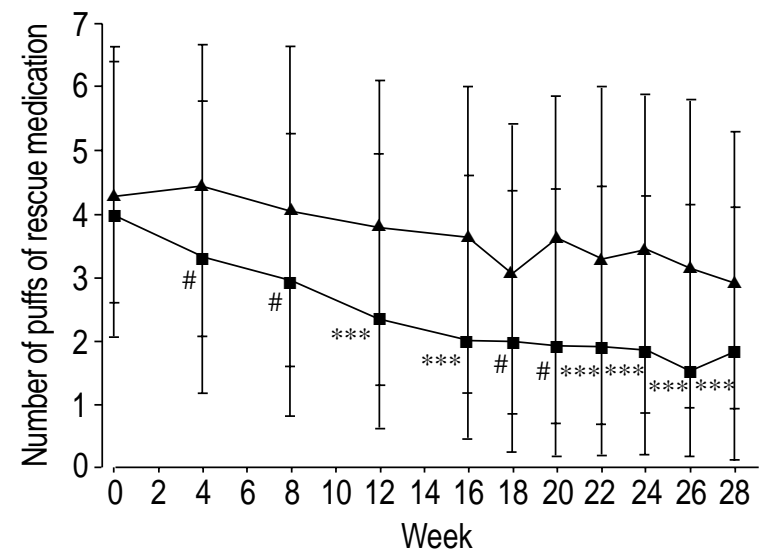

Fig. 4.- Number of puffs of salbutamol rescue medication taken daily during the stable-steroid (weeks 0-15) and steroid-reduction phases (weeks 15-28). Intent-to-treat population. Data are medians with interquartile range. $\boldsymbol{\Delta}$ : placebo; $\mathbf{0}$ : omalizumab. ${ }^{\#}: \mathrm{p}<0.005$; $* * *: \mathrm{p}<0.001$ versus placebo. 

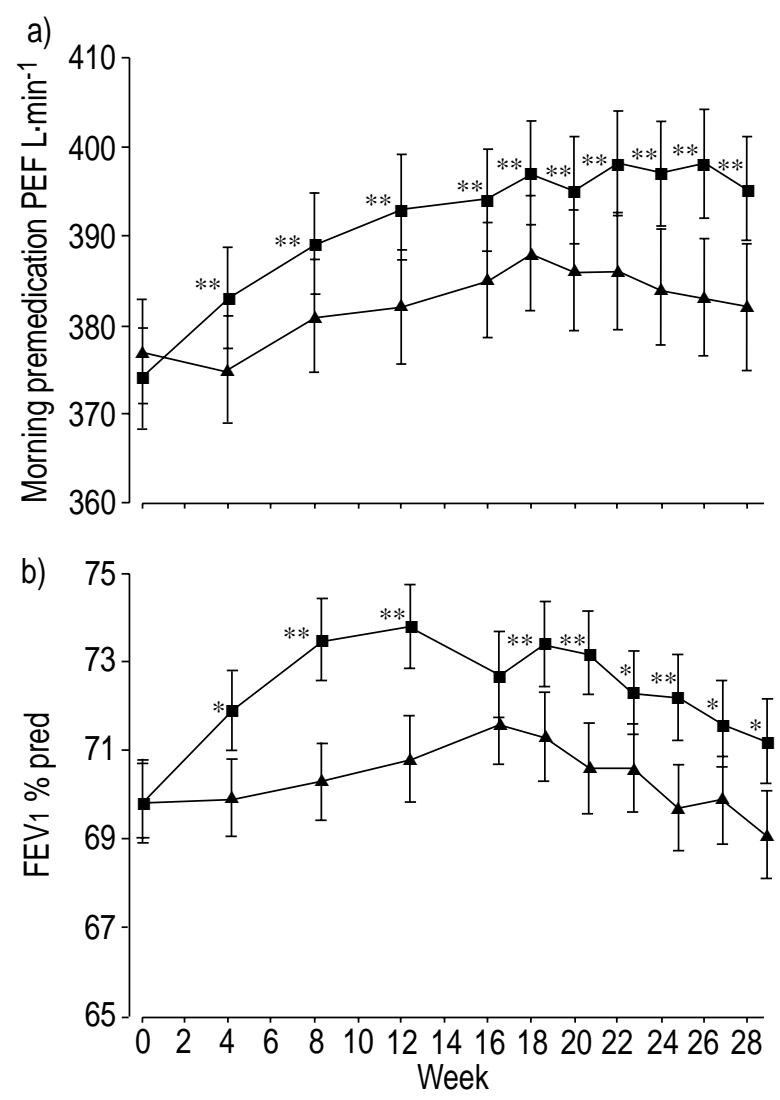

Fig. 5.-a) Morning peak expiratory flow (PEF) values and b) forced expiratory volume in one second (FEV1) values as $\%$ pred during the stable-steroid (weeks 0-15) and steroid-reduction phases (weeks 15-28). Intent-to-treat population. Data are means \pm SE. $\boldsymbol{\Delta}$ : placebo; $\mathbf{\square}$ : omalizumab. ${ }^{*}: \mathrm{p}<0.05 ;{ }^{*}: \mathrm{p}<0.01$ versus placebo.

and Chiari type I malformation. All were not suspected to be drug-related. Six patients $(2.2 \%)$ in the placebo group and none in the omalizumab group experienced asthma exacerbations resulting in hospitalization.

Five $(1.8 \%)$ patients on placebo compared with none on omalizumab withdrew prematurely because of adverse events.

One case of mild proteinuria in a patient treated with omalizumab was assessed by a nephrologist. A renal biopsy analysis showed only minor nonspecific changes with no evidence of immune complex disease. The proteinuria was considered to be related to hypertension.

The overall incidence of adverse events was comparable between the treatment groups $(\mathrm{p}=0.504)$ as was the overall incidence of suspected drug-related adverse events $(p=0.183)$. Fatigue and paresthesia were the most commonly suspected drug-related adverse events occurring in $1.1 \%$ of patients receiving omalizumab and in none receiving placebo. Three patients $(1.1 \%)$ in each group had suspected drugrelated headache. Local injection site symptoms were associated with $11.8 \%$ of omalizumab injections compared to $7.7 \%$ of placebo injections. The most frequent injection site event in both groups was bruising. The symptoms that were more frequent on omalizumab were redness, warmth and itching. The majority of these events were mild in severity. Of the seven patients who experienced urticaria during the study, five were receiving placebo. None of these events were severe.

No patient on omalizumab developed anti-omalizumab antibodies.

\section{Discussion}

The symptoms of allergic diseases are due to an inflammatory process where IgE-mediated events play a crucial role [6-10]. By decreasing serum free IgE levels, omalizumab (rhuMAb-E25, Xolair ${ }^{\mathrm{TM}}$ ) provides a specific method to treat these diseases, irrespective of the particular allergen involved. Previous studies in allergic asthmatics $[15,16]$ have indicated that omalizumab reduces the allergeninduced late asthmatic response, airway hyperresponsiveness and sputum eosinophilia, suggesting that this agent may have a long-term anti-inflammatory effect.

In asthma, acute exacerbations are the clinical expression of inadequate disease control with a strong impact on disease morbidity, mortality, quality of life and total costs of illness [1, 2, 27]. This recognition has increasingly induced investigators to choose exacerbation rate as the primary outcome measure in clinical trials evaluating the effectiveness of new anti-asthmatic drugs [28, 29].

The results of this randomized, double-blind, placebo-controlled study indicate that the addition of omalizumab in allergic asthmatics who remain uncontrolled despite regular treatment with inhaled corticosteroids, simultaneously reduces both asthma exacerbations and corticosteroid requirement while improving other parameters of disease control.

There were $58 \%$ fewer asthma exacerbations per patient during the stable-steroid phase in the omalizumab group than in the placebo group. Significantly lower exacerbation rates were also observed in the omalizumab group as compared to the placebo group during the steroid-reduction phase, with $52 \%$ fewer episodes despite the greater reduction in the BDP dose and use of salbutamol rescue medication in the patients on omalizumab.

The steroid-reduction phase of 3 months may have been too short to fully observe an asthma worsening. However, in a study examining exacerbations of asthma induced by corticosteroid withdrawal, where the daily dose of BDP was reduced by $200 \mu \mathrm{g}$ at weekly intervals [30], each subject developed an exacerbation of symptoms between 7 and 26 days after onset of steroid reduction. In addition, according to the data from a retrospective study of $>12,000$ asthmatic patients [31], the estimated mean number of asthma exacerbations per year in patients with moderate-to-severe asthma (BTS treatment steps 3-5) would be $2-2.5$ per patient [31]. Therefore, the mean number of asthma exacerbations experienced by the patients on placebo during the 3 months of the steroid-reduction phase $(0.75)$ would be higher than that expected in a similar population for a similar period of observation, while the mean number of asthma 
exacerbations experienced by the patients on omalizumab over the same period would be $>50 \%$ lower.

The benefit of treatment with omalizumab is supported by the evidence that no patient in the omalizumab group was hospitalized due to asthma exacerbations versus six patients in the placebo group. Furthermore, the number of withdrawals was two-fold lower on omalizumab than on placebo (19 versus 40 ).

There was a remarkable ability of placebo-treated patients to reduce the corticosteroid dose $(50 \%)$. This may be due to an excessive BDP dose at entry, but the patients were still symptomatic at this dose. Alternatively, it may be the expression of an improved compliance with BDP treatment resulting from the frequent assessment by a physician and encouragement to adhere to therapeutic regimens during the study. Despite this marked placebo effect, BDP reduction was significantly greater in omalizumabtreated patients $(83 \%)$, and more than twice as many patients in the omalizumab group $(43 \%)$ as in the placebo group (19\%) completely withdrew BDP.

Results of the other secondary efficacy variables reflecting the degree of asthma control were consistent with those of the primary variables, including symptoms score, morning PEF and FEV1, with treatment differences invariably in favour of omalizumab during both the stable-steroid and steroid-reduction phases.

The absolute improvement in morning PEF and FEV1 observed in the omalizumab group was relatively small. However, patients enrolled in this study were already receiving the anti-inflammatory therapy recommended by current guidelines for treatment of chronic persistent asthma of similar severity $[1,2]$. The addition of another agent with antiinflammatory effects, which does not possess bronchodilator properties, is not expected to provide large improvements in airflow obstruction outside asthma exacerbations in these circumstances.

The safety profile of omalizumab was excellent, and treatment was well tolerated. There were no drugrelated serious adverse events.

The results of this study confirm and extend those reported in an initial trial investigating the efficacy of omalizumab administered by intravenous injection [17]. The subcutaneous route of administration and the dosing schedule adopted in the present study are those proposed for therapeutic use and, therefore, the results have more practical relevance. Other original aspects of this work include the selection of the primary end-point (reduction in the number of asthma exacerbations versus an improvement in asthma symptom score), a larger and more homogeneous population of asthmatic patients with a wider age range, and an extended duration of both treatment phases.

In conclusion, the study indicates that therapy with omalizumab is effective and safe in allergic asthma and offers an innovative solution to control the disease while reducing corticosteroid consumption. Its optimal use might be in the long-term management of patients with a difficult-to-treat disease, those suffering from persistent symptoms despite conventional corticosteroid treatments, and those who need a high dose of inhaled corticosteroids or have sideeffects associated with their use. The infrequent dosing schedule may greatly enhance compliance with treatment in allergic asthmatic patients requiring complex therapeutic regimens. In addition, since omalizumab is effective and safe in the management of allergic rhinitis [18, 20], patients suffering from both conditions concomitantly may also benefit from treatment.

\footnotetext{
Acknowledgements. The following investigators, listed by country, also contributed patient data: Australia, R. Ruffin, R. Scicchitano; Austria, G. Kaik; Germany, G. Kunkel, C. Kroegel, K-C. Bergmann, H. Leiner; Italy, G.W. Canonica, G. D'Amato, G. Moscato, E. Marchi; the Netherlands, R. Aalbers, J.P.H.M. Creemers, E.F. Dubois, A. Greefhorst, P.B. Luursema, A. Sips; South Africa, A.P. Foden, J. Terblanche; UK, A. Millar, M. Spiteri, A. Tattersfield, F. Chung; USA, G. Bensch, T. Casale, L. Ford, A. Nayak, H. Beede, J. Yarbrough, S. Fineman, N. LaHood, G.G. Shapiro, J. Wolfe, E. Lisberg, T. Lee, A. Martin, H. Windom, B.Q. Lanier, W. Berger. The Novartis Clinical Project Leader was P. Rohane.
}

\section{References}

1. National Asthma Education Prevention Program Expert Panel. Expert Panel No.2: Guidelines to the Diagnosis and Management of Asthma. Bethesda, MD, National Heart and Blood Institute, 1997. NIH publication No. 97-4051.

2. British Asthma Guidelines Co-ordinating Committee. British guidelines on asthma management: 1995 review and position statement. Thorax 1997; 52: S1-S24.

3. Barnes PJ. Current issues for establishing inhaled corticosteroids as the antiinflammatory agents of choice in asthma. J Allergy Clin Immunol 1998; 101: S427-S433.

4. Barnes PJ, Woolcock AJ. Difficult asthma. Eur Respir $J$ 1998; 12: 1209-1218.

5. Proceedings of the ATS workshop on refractory asthma. Current understanding, recommendations and unanswered questions. Am J Respir Crit Care Med 2000; 162: 2341-2351.

6. Spector SL. Allergic inflammation in upper and lower airways. Ann Allergy Asthma Immunol 1999; 83: 435444.

7. Drazen JM, Arm JP, Austen KF. Sorting out the cytokines of asthma. Commentary. J Exp Med 1996; 183: $1-5$.

8. Hamelmann E, Tadeda K, Oshiba A, et al. Role of $\mathrm{IgE}$ in the development of allergic airway inflammation and airway hyperresponsiveness - a murine model. Allergy 1999; 54: 297-305.

9. Wills-Karp M. Immunologic basis of antigen-induced airway hyperresponsiveness. Annu Rev Immunol 1999; 17: 255-281

10. Williams CM, Galli SJ. The diverse potential effector and immunoregulatory roles of mast cells in allergic disease. J Allergy Clin Immunol 2000; 105: 847-859.

11. Burrows B, Martinez FD, Halonen M, Barbee RA, 
Cline MG. Association of asthma with serum $\operatorname{IgE}$ and skin-test reactivity to allergens. $N$ Engl J Med 1989; 320: 271-277.

12. Sears MR, Burrows B, Flannery EM, Herbison GP, Hewitt CJ, Holdaway MD. Relation between airway responsiveness and serum $\operatorname{IgE}$ in children with asthma and in apparently normal children. $N$ Engl J Med 1991; 325: 1067-1071.

13. Sunyer J, Anto JM, Sabria J, et al. Relationship between serum $\operatorname{IgE}$ and airway responsiveness in adults with asthma. J Allergy Clin Immunol 1995; 95: 699-706.

14. Sherrill DL, Stein R, Halonen M, et al. Total serum $\mathrm{IgE}$ and its association with asthma symptoms and allergic sensitization among children. J Allergy Clin Immunol 1999; 104: 28-36.

15. Fahy JV, Fleming HE, Wong HH, et al. The effect of an anti-IgE monoclonal antibody on the early- and late-phase responses to allergen inhalation in asthmatic subjects. Am J Respir Crit Care Med 1997; 155: $1828-1834$.

16. Boulet LP, Chapman KR, Cote J, et al. Inhibitory effects of an anti-IgE antibody E25 on allergeninduced early asthmatic response. Am J Respir Crit Care Med 1997; 155: 1835-1840.

17. Milgrom H, Fick RB, Su JQ, et al. Treatment of allergic asthma with monoclonal anti-IgE antibody. $N$ Engl J Med 1999; 341: 1966-1973.

18. Casale TB, Bernstein IL, Busse WW, et al. Use of an anti-IgE humanised monoclonal antibody in ragweedinduced allergic rhinitis. J Allergy Clin Immunol 1997; 100: $110-121$.

19. Casale T, Racine A, Sallas W, Fowler Taylor A, Gupta N, Rohane P. Relationship between the clinical efficacy of rhuMAb-E25 (E25) and serum free $\operatorname{IgE}$ in seasonal allergic rhinitis. J Allergy Clin Immunol 2000; 105: S357.

20. Aderoth E, Rak S, Haahtela T, et al. Recombinant humanized $\mathrm{mAb}-\mathrm{E} 25$, an anti-IgE $\mathrm{mAb}$, in birch pollen-induced seasonal allergic rhinitis. $J$ Allergy Clin Immunol 2000; 106: 253-259.
21. Presta LG, Lahr SJ, Shields RL, et al. Humanization of an antibody directed against IgE. J Immunol 1993; 151: 2623-2632.

22. Presta L, Shields R, O'Connell L, et al. The binding site on human immunoglobulin $\mathrm{E}$ for its high affinity receptor. J Biol Chem 1994; 269: 26368-26373.

23. Shields RL, Werther WR, Zioncheck K, et al. AntiIgE monoclonal antibodies that inhibit allergenspecific histamine release. Int Arch Allergy Immunol 1995; 107: 412-413.

24. Jardieu PM, Fick RB Jr. IgE inhibition as a therapy for allergic disease. Int Arch Allergy Immunol 1999; 118: 112-115.

25. Coyle AJ, Wagner K, Bertrand C, Tsuyuki S, Bews J, Heusser C. Central role of immunoglobulin (Ig) E in the induction of lung eosinophil infiltration and $\mathrm{T}$ helper 2 cell cytokine production: inhibition by a nonanaphylactogenic anti-IgE antibody. J Exp Med 1996; 183: $1303-1310$.

26. American Thoracic Society (American Lung Association). Standard for the diagnosis and care of patients with chronic obstructive pulmonary disease (COPD) and asthma. Am Rev Respir Dis 1987; 136: 225-244.

27. Barnes PJ, Jonsson B, Klim JB. The costs of asthma. Eur Respir J 1996; 9: 636-642.

28. Pauwels RA, Löfdahl C-G, Postma DS, et al. Effect of inhaled formoterol and budesonide on exacerbations of asthma. N Engl J Med 1997; 337: 1405-1411.

29. Shrewsbury S, Pyke S, Britton M. Meta-analysis of increased dose of inhaled steroid or addition of salmeterol in symptomatic asthma (MIASMA). BMJ 2000; 320: 1368-1373.

30. Gibson PG, Wong BJ, Hepperle MJ, et al. A research method to induce and examine a mild exacerbation of asthma by withdrawal of inhaled corticosteroid. Clin Exp Allergy 1992; 22: 525-532.

31. Hoskins G, McCowan C, Neville RG, Thomas GE, Smith B, Silverman S. Risk factors and costs associated with an asthma attack. Thorax 2000; 55: 19-24. 